\title{
Advanced Oxidation Processes for the Removal of Algal Cells and Cyanotoxins from Drinking Water
}

\author{
Qingliang Liu ${ }^{1, a}$, Huiling Liu ${ }^{1, b}$, Shujie $\mathrm{Wu}^{1, \mathrm{c}}$ and Ziheng Duan ${ }^{1, \mathrm{~d}}$ \\ ${ }^{1}$ State Key Laboratory of Urban Water Resources and Environment, Harbin Institute of Technology, \\ Harbin 150090, China; \\ ahitliuql@qq.com, bhlliu2002@163.com, '764652326@qq.com, d1101985547@qq.com
}

Keywords: drinking water, advanced oxidation processes, algal.

\begin{abstract}
Although traditional processing methods can be effective for removal of algal blooms of cells, also has the potential to provide a major breakthrough of microcystins in the course of normal operation. As a result, the presence of more advanced processing of algal toxins in drinking water treatment water. Along with the more traditional method of recognizing the need to oxidation, advanced oxidation process is a promising technology available for algal toxins in drinking water damage. Some advanced oxidation is currently being developed to detect microcystin damage. This study provides an introduction to the oxidation technology and its application, in order to eliminate or drinking water in cells and destroy red tide algae toxins.
\end{abstract}

\section{Introduction}

With the further development of the economy, it is bound to further increase the amount of sewage, and eutrophic water governance is a long-term and systematic project, so for a long period of time, blue-green algae blooms will still exist, and even more serious. When the outbreak of blue-green algae blooms, can lead to death portion of the biological and livestock, and the water supply as water quality deterioration. Algae can interfere with conventional water treatment processes in the coagulation, sedimentation and filtration of these solid-liquid separation process, such as a substantial increase in coagulant dosage, algae penetrate filter and high turbidity, etc., and some cyanobacteria produce algae toxins, cause taste and odor problems, would lead to serious incidents of urban water supply. Currently drinking water treatment by means of high algae water is still all the disadvantages, the development of new algae removal process has important guiding significance for drinking water treatment.

\section{Advanced Oxidation Processes for the Removal of Algal Cells}

Chlorine. MA et al. showed that chlorine had no significant effect on the majority of M. aeruginosa cell shape [1]. DALY et al that affect the integrity of the algal cells chlorine with chlorine dosage is increased [2]. And in order to continue to achieve the effect of algal cell lysis requires sustained investment and chlorine. Before oxidation cyanobacterial cells were smooth spherical, and in the oxidation of cell shape change significantly, which further proved that there $\mathrm{CLO}_{2}$ loss of integrity of the cell capacity.

Ozone. Ozone destruction of algal cells are two main ways: an indirect reaction direct reaction of ozone molecules and $\mathrm{OH}$ - radicals, the two can attack cell walls and membranes, undermine the integrity of the film, so that cellular material released from cells and cells damaged split into pieces. Ozone destruction of algal cells are two main ways: an indirect reaction direct reaction of ozone molecules and $\mathrm{OH} \cdot$ radicals, the two can attack cell walls and membranes, undermine the integrity of the film, so that cellular material released from cells and cells damaged split into pieces [3-4]. Miao et al confirmed by SEM the influence of ozone on algal cell morphology [5]. In this study, after ozone treatment the cell structure and cell wall have changed. In the natural environment, a single M. aeruginosa cells spherical or ellipsoidal. With the increase of ozone dose $(1 \mathrm{mg} / \mathrm{L}$ gradually increased to $5 \mathrm{mg} / \mathrm{L}$ ), the cell wall can be clearly observed morphological changes, increased cytoplasm and 
release more cell damage. XIE et al. contrast ozone by flow cytometry for lysis of algal cells, discovery and ozone effects on algal cell lysis obvious effect, the molar concentration of ozone is far lower than even potassium permanganate, its effect is still due to the latter [6].

Photolysis and UV/Hydrogen Peroxide. OU et al studied the UV-C (short-wave ultraviolet $254 \mathrm{~nm}$ ) of M. aeruginosa damaging cells [7]. The study found, UV-C dose of cells showed a significant contraction folds and $1.4 \times 10^{3} \mathrm{~mJ} \mathrm{~cm}^{-2}$, while continuing to increase the dose to $4.2 \times$ $10^{3} \mathrm{~mJ} \mathrm{~cm}^{-2}$ and $5.6 \times 10^{3} \mathrm{~mJ} \mathrm{~cm}^{-2}$, stromal cells was observed on the cell structure. It was fragmented, then off, and then observed cell necrosis and dissolution. When a dose of $8.4 \times 10^{3} \mathrm{~mJ} \mathrm{~cm}^{-2}$ cell collapse visible separation of abundant intracellular spillage, no intact cells are present.

Potassium Permanganate. The earliest permanganate for the removal of algae generally considered permanganate for microcystin degradation is usually effective, but it can not effectively penetrate or lysed cells. In the study of natural surface water removal MC also found that this phenomenon, also proposed in the practical application, it need to use the appropriate means to remove the newly formed manganese oxide [7]. Li et explanation of this phenomenon is shown, permanganate and algal cells first reaction upon contact with extracellular substance EOM, until permanganate on the cell surface accumulation reaches a certain amount, the middle of the stage[8]. It did not significantly affect the integrity of the cell. And then, near the cell wall lining of potassium permanganate and a large number of algal cells inactivated.

\section{Advanced Oxidation Processes for the Removal of Cyanotoxins}

Chlorine. Chlorine can degrade microcystins, but efficiency depends on the treated water quality conditions, and is heavily influenced by $\mathrm{pH}$. That there are limits to the practical engineering application. ACERO et al. found that the apparent second-order rate constants of chlorine degradation MC-LR from $4.75 \times 10^{2} \mathrm{M}^{-1} \mathrm{~s}^{-1}(\mathrm{pH}=4.8)$ is gradually reduced to $9.8 \mathrm{M}^{-1} \mathrm{~s}^{-1}(\mathrm{pH}=8.8)$ [10]. MEREL et al. showed that exist naturally in water algae toxins and NOM will compete disinfectants, reducing chlorine degradation efficiency of algal toxins [11]. Drinking water treatment under the conditions found that when a high humic acid content in the raw water, chlorine dioxide oxidation do the removal of the original algal toxins is very weak, even negligible, Effect of water conditions on the reaction rate determines the chlorine dioxide is not ideal algae water treatment agent [12]. Also a lot of research on alternative chlorine with chloramine showed that the reaction constant learning power is low, the removal of microcystin is invalid.

Ozone. Shawwa and other shows that ozone destruction for microcystin toxin is extremely rapid[13]. Many studies have found that water quality conditions for ozone destruction microcystin is influential. Shawwa et al also found that in the presence of natural organic matter degradation rate decreases.Earlier studies found that, $\mathrm{pH}$ conditions affect the degradation rate [14]. Rositano and others also showed that for the destruction of microcystin, ozone compared to other oxidizing agents such as chlorine, peroxide, permanganate and so has a faster speed. Ozone destruction of microcystin Adda due to ozone attack key byproduct molecule amino lost toxicity after lysis.

Potassium Permanganate. Permanganate similar to ozone, it is also part of the attack Adda cause toxic algal toxin is destroyed. Early studies with potassium permanganate degradation of microcystin Chen et al found that between $15 \sim 30^{\circ} \mathrm{C}$, increasing the concentration of the reaction temperature and oxidant can increase the degradation rate of MC-RR. Under the experimental conditions the half-life of not more than 1min, MC-RR to achieve effective removal (99.5\%) within 10min [15]. Meanwhile, Chen et al studied the $\mathrm{pH}$ in the MC-RR degradation rate 5.0,6.7,9 time, concluded respectively: MC-RR under acidic conditions degrade faster, but the difference was small. This conclusion is also RODRÍGUEZ et al. demonstrated that when they found between $\mathrm{pH} 6.2$ to 8.2, its effect on the reaction rate can be ignored. MC rate by comparing different types of oxidant degradation can be found, the rate of potassium permanganate is much lower than MC can quickly react with ozone $\left(\mathrm{k}>10^{4} \mathrm{M}^{-1} \mathrm{~s}^{-1}\right)[10]$.

Photolysis and UV/Hydrogen Peroxide. Photocata lytic oxidation method as an alternative to the traditional method of treatment is an environmentally friendly means. Natural environment 
microcystin can in daylight ultraviolet irradiation decomposition, mainly due to the electron-hole pairs and hydroxyl radical $(\bullet \mathrm{OH})$ caused Adda side chain of conjugated double bonds broken, so as to eliminate microcystin toxicity effects [16]. In view of the ultraviolet rays in sunlight spectrum in the proportion of only a limited part, and ultraviolet radiation on algae toxin decomposition dependence and intensity, and therefore have developed a variety of methods behind and derivatives based on ultraviolet degradation MC [17]. And QIAO et al found that in $3.66 \mathrm{~mW} / \mathrm{cm}^{2}$ light intensity measured microcystin half life of about 29 minutes [18]. Presumably due to differences between the two different performance conditions and water quality caused by photochemical reactor.

Fenton Reaction. Fenton reaction has been a lot of research on treatment for microcystin. GAJDEK et al studies have shown that the use of the Fenton reaction can be achieved complete degradation of microcystin in 30 minutes [19]. BANDALA et al found that with the ultraviolet light, namely light Fenton method can effectively improve the treatment effect. Fenton system to MC-LR highest degradation rate is only 60 percent, while light Fenton oxidation system 30 to 40 minutes can achieve 100\% MC-LR degradation [20]. Zhong et al. experimentally confirmed, under the best conditions, the Fenton reaction to the destruction of MC-RR can reach more than 99\% [21]. Al Momani et al also proved toxins can be removed within 90 seconds toxoid [22].

\section{Summary}

Currently, advanced oxidation processes for the removal of algae have been numerous studies, but still inadequate, the problem is mostly concentrated in two areas: First, the effect is not ideal. Conventional drinking water treatment processes such as the removal of chlorine-based and other algae is not ideal, cannot meet the drinking water indicators, algae outbreak in the season can not be used. At the same time, the majority of advanced oxidation processes for water quality demanding, when there are other contaminants in water, it will affect the removal of algae, the practical application is very hard; second, follow-up questions raised. Ozone, UV and other advanced oxidation methods often cause cracking of algal cells, a large number of cell contents released into the water, but will increase the difficulty of treatment. And, also with the most progressive oxidation cell contents released into the water produced by the reaction of harmful disinfection byproducts. In addition, as used in drinking water treatment processes, the need to control its costs. In view of the above points, there remains a need to find good an effect, try not to produce toxic byproducts subsequent biological and low-cost algae removal means.

\section{References}

[1] M. K. Ramseier, U. von Gunten, Pietro Freihofer, and F. Hammes, Kinetics of membrane damage to high (HNA) and low (LNA) nucleic acid bacterial clusters in drinking water by ozone, chlorine, chlorine dioxide, monochloramine, ferrate(VI), and permanganate, Water Research. 45 (2011) 1490-1500. 3.

[2] R. I. Daly, L. Ho, and J. D. Brookes, Effect of Chlorination on Microcystis aeruginosaCell Integrity and Subsequent Microcystin Release and Degradation, Environ. Sci. Technol. 41 (2007) 4447-4453. 12.

[3] C. W. K. Chow, J. House, R. M. A. Velzeboer, M. drikas, M. D. Burch, and D. A. steffensen, The Effect of Feeric Chloride Flocclation on Cyanobacterial Cells,Water Research. 32 (1998) 808-814. 3.

[4] B.C.Hitzfeld, S.J. Hoger, and D.R. Dietrich, Cyanobacterial toxins: removal during drinking water treatment, and human risk assessment, Environmental Health Perspectives. 108 (2000) 113-122.

[5] H. Miao and W. Tao, The mechanisms of ozonation on cyanobacteria and its toxins removal, Separation and Purification Technology. 66 (2009) 187-193. 1. 
[6] P. Xie, J. Ma, J. Fang, Y. Guan, S. Yue, X. Li, and L. Chen, Comparison of Permanganate Preoxidation and Preozonation on Algae Containing Water: Cell Integrity, Characteristics, and Chlorinated Disinfection Byproduct Formation, Environ. Sci. Technol. 47 (2013) 14051-14061. 24.

[7] H. Ou, N. Gao, Y. Deng, H. Wang, and H. Zhang, Inactivation and degradation of Microcystis aeruginosa by UV-C irradiation, Chemosphere. 85 (2011) 1192-1198. 7.

[8] J. Pietsch, K. Bornmann, and W. Schmidt, Relevance of Intra- and Extracellular Cyanotoxins for Drinking Water Treatmen, Acta Hydrochimica Et Hydrobiologica. 30 (2002) 7-15.1.

[9] L. Li, C. Shao, T.-F. Lin, J. Shen, S. Yu, R. Shang, D. Yin, K. Zhang, and N. Gao, Kinetics of Cell Inactivation, Toxin Release, and Degradation during Permanganation of Microcystis aeruginosa, Environ. Sci. Technol. 48 (2014) 2885-2892. 5.

[10]J. L. Acero, E. Rodríguez, and J. Meriluoto, Kinetics of reactions between chlorine and the cyanobacterial toxins microcystins, Water Research .39 (2005) 1628-1638. 8.

[11]S. Merel, M. ClEment, and O. Thomas, State of the art on cyanotoxins in water and their behaviour towards chlorine, Toxicon. 55 (2010) 677-691. 4.

[12]T. P. J. Kull, O. T. Sjövall, M. K. Tammenkoski, P. H. Backlund, and J. A. O. Meriluoto, Oxidation of the Cyanobacterial Hepatotoxin Microcystin-LR by Chlorine Dioxide: Influence of Natural Organic Matter, Environ. Sci. Technol. 40 (2006) 1504-1510. 5.

[13] A.R. Shawwa and D.W. Smith, Kinetics of microcystin-LR oxidation by ozone. Ozone: Science and Engineering, Ozone: Science and Engineering. 23 (2001) 161-170.

[14]J. Rositano, B.C. Nicholson, and P. Pieronne, Destruction of cyanobacterial toxins by ozone, Ozone: Science and Engineering. 20 (1998) 223-238.

[15] X. Chen, B. Xiao, J. Liu, T. Fang, and X. Xu, Kinetics of the oxidation of MCRR by potassium permanganate, Toxicon. 45 (2005) 911-917. 7.

[16]X. Huo, D.-W. Chang, J.-H. Tseng, M. D. Burch, and T.-F. Lin, Exposure of Microcystis aeruginosato Hydrogen Peroxide under Light: Kinetic Modeling of Cell Rupture and Simultaneous Microcystin Degradation, Environ. Sci. Technol. 49 (2015) 5502-5510. 9.

[17]H. Sakai, H. Katayama, K. Oguma, and S. Ohgaki, Kinetics of Microcystis aeruginosa Growth and Intracellular Microcystins Release after UV Irradiation, Environ. Sci. Technol. 43 (2009) 896-901. 3.

[18] R.-P. Qiao, N. Li, X.-H. Qi, Q.-S. Wang, and Y.-Y. Zhuang, Degradation of microcystin-RR by UV radiation in the presence of hydrogen peroxide, Toxicon. 45 (2005) 745-752. 6.

[19]P. Gajdek, Z. Lechowski, T. Bochnia, and M. KeÎpczynÂski,Decomposition of microcystin-LR by Fenton oxidation, Toxicon. 39 (2001) 1575-1578.

[20]E. R. Bandala, D. Martínez, E. Martínez, and D. D. Dionysiou, Degradation of microcystin-LR toxin by Fenton and Photo-Fenton processes, Toxicon. 43 (2004) 829-832. 7.

[21]Y. Zhong, X. Jin, R. Qiao, X. Qi, and Y. Zhuang, Destruction of microcystin-RR by Fenton oxidation, Journal of Hazardous Materials. 167 (2009) 1114-1118. 1-3

[22]F. Al Momani, D. W. Smith, and M. Gamal El-Din, Degradation of cyanobacteria anatoxin-a by advanced oxidation processes, Journal of Hazardous Materials. 150 (2008) 85-93. 1. 